\title{
Bioactivites of Penicillium citrinum isolated from a medicinal plant Swertia chirayita
}

\author{
Hemant Sharma ${ }^{1}$ - Arun Kumar Rai ${ }^{1} \cdot$ Rajen Chettri ${ }^{2} \cdot$ Poonam Singh Nigam $^{3}$ (D) \\ Received: 1 March 2021 / Revised: 14 July 2021 / Accepted: 19 July 2021 / Published online: 2 August 2021 \\ (c) The Author(s) 2021
}

\begin{abstract}
Endophytes associated with plants have the property to produce active biomolecules with their possible applications in agroindustrial sectors. This study provides a project work on analyzing various activities of fungal endophytes isolated from Swertia chirayita of Sikkim Himalayan region. Among several fungal endophytes screened, isolate UTCRF6 was found most active with the secretion of enzymes protease, cellulase, amylase and chitinase, as well as other metabolites Indoleacetic acid and siderophores. This endophyte was found active in restricting the growth of phyto-pathogens, including strains of Fusarium solani, Colletotrichum gloeosporioides, Alternaria alternata, Pestalotiopsis theae and Sclerotinia sclerotiorum. Morphological and molecular studies of this endophytic fungus showed similarity with Penicillium citrinum.
\end{abstract}

Communicated by Erko Stackebrandt.

Poonam Singh Nigam

p.singh@ulster.ac.uk

1 Department of Botany, Sikkim University, 6th Mile Tadong, Gangtok, Sikkim, India

2 Department of Botany, Sikkim Government Science College, Chakung, Sikkim, India

3 Biomedical Sciences Research Institute, Ulster University, Coleraine, Northern Ireland 


\section{Graphic abstract}

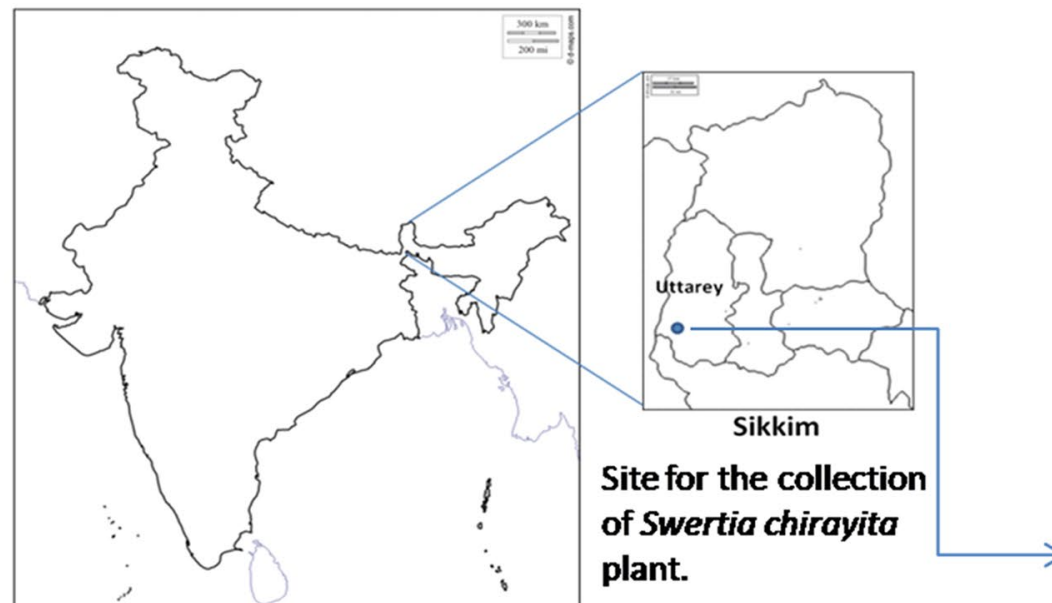

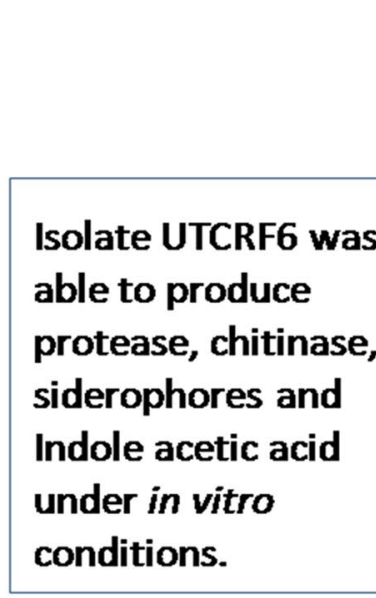

西

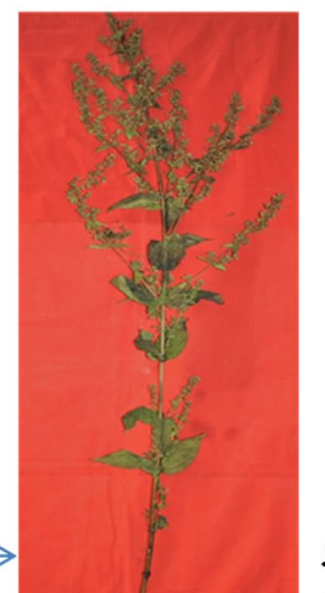

Swertia chirayita plant.

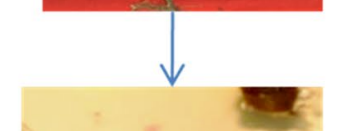

Growth of an endophyte from a segment of the plant in PDA medium.

Isolate UTCRF6 growing in PDA medium.

\section{Phylogenetic chart showing relationship of UTCRF6 against other species of Penicilium genus.}

Keywords Fungal endophytes $\cdot$ Fusarium $\cdot$ Protease $\cdot$ Chitinase $\cdot$ Amylase $\cdot$ Enzymes $\cdot$ Phytopathogen

\section{Introduction}

Microorganisms residing within plant tissues without causing apparent harm to their host for the most part of the life cycle are known as endophytes. Endophytic microbes exist in close association with plant tissues maintaining a strong symbiotic relationship. Endophytes have been isolated from every type of plant tissues studied so far (Deshmukh et al. 2020). Symbiotic relationship between plants and fungi date back to the time when terrestrial plants started to colonize the land and fungi may have played a crucial role to facilitate the colonization (Redecker et al. 2000).
Apart from plant growth promotion, endophytes have been reported to neutralize invading phytopathogens or produce factors that induce host resistance (Vega 2018). Endolichenic fungi represent a relatively untapped bioresource future biopharmaceuticals (Agrawal et al. 2020). These mysterious microorganisms have been associated with the bio-fertilization potential such as solubilization of inorganic phosphates, production of siderophores, and secretion of plant growth-promoting hormones (Zhang et al. 2018). These endophytes also produce important enzymes, such as chitinase, which are useful in solid seafood waste management (Thomas et al. 2020), and also help in inducing host resistance to phytopathogens (Rajulu et al. 2011), 
as well as produce antifungal metabolites against common phytopathogens (Shentu et al. 2014). These properties of endophytes make them a suitable candidate for accessing their potential in sustainable agriculture and industrial sectors, protecting and utilizing natural bioresources.

Swertia chirayita (Roxb. ex Fleming) H. Karst. is a member of Gentianaceae family that typically grows at an elevation of 1200-2100 m above mean sea level and is dispersed across the Himalayan belt from Kashmir to Bhutan and Khasi hills (Kumar and Staden 2016). Among 135 recorded species of Swertia genus, 40 species are found in India with 8 of them found in Sikkim and surrounding Himalayan region (Envis centre Sikkim, Forest, Environment \& Wildlife Management Department, Government of Sikkim, 2011). Swertia chirayita is considered significantly superior to other species of the same genus due to its medicinal uses (Kumar and Staden 2016), which may be attributed to the presence of a higher concentration of bioactive metabolites (Kshirsagar et al. 2020). Narrow belt of a suitable geographical habitat and common use in herbal medicines have typically resulted in overexploitation of this species (Pradhan and Badola 2012; Rai et al. 2000). Therefore, an investigation of the endophytes associated with Swertia chirayita requires work on their isolation and characterization before the loss of this valuable bioresource from its natural habitat.

Therefore, this project was planned in collaboration with three research institutes (in India and Northern Ireland) and undertaken to secure such valuable microflora and test for their hidden potential. The main aim was to isolate endophytes of S. chirayita sampled from the surrounding area of Uttarey located at $35 \mathrm{~km}$ from Gyalshing in West district of Sikkim (E $088^{\circ} 08.273^{\prime}$, N 2728.164', Elevation 2456 m), and to study screened isolates for their bioactivities with potential applications in sustainable agriculture-resources.

\section{Materials and methods}

\section{Culture media}

Potato Dextrose Agar (HiMedia, India) and Water Agar (Agar, $20.0 \mathrm{~g}$; Distilled water, $1000.0 \mathrm{ml}$ ) were used for isolation, sub-culturing and storing of endophytes from its host Swertia chirayita samples. Water Agar (WA) and Potato Dextrose Agar (PDA) were supplemented with Streptomycin $(50 \mu \mathrm{g} / \mathrm{ml})$ targeting the growth of fungi and inhibiting bacterial infection. Other media used for screening the endophytes for different activities were: Minimal salt agar (Dipotassium hydrogen phosphate, $7.0 \mathrm{~g}$; Monopotassium phosphate, $2.0 \mathrm{~g}$; Sodium citrate, $0.5 \mathrm{~g}$; Magnesium sulphate, $0.1 \mathrm{~g}$; Ammonium sulphate, $1.0 \mathrm{~g}$; Agar, $15.0 \mathrm{~g}$; Distilled water, $1000.0 \mathrm{ml}$; $\mathrm{pH}, 7.0 \pm 0.2$ ); Chitinase medium, Pikovskaya's Agar medium, Starch Agar, Skim Milk Agar,
CMCase Agar, Potato Dextrose Broth (all obtained from HiMedia, India).

\section{Test pathogens}

Phytopathogens with relevance to the crops of Sikkim state were procured from the Division of Plant Pathology, Indian Agricultural Research Institute, New Delhi, India. Fusarium solani ITCC 7453, Colletotrichum gloeosporioides ITCC 5514, Alternaria alternate ITCC 7415, Pestalotiopsis theae ITCC 6599 and Sclerotinia sclerotiorum ITCC 7853 were selected to assess the antagonistic potential of endophytes isolated from S. chirayita. All phytopathogens were maintained on PDA slants.

\section{Sampling and identification of Swertia chirayita}

With the aim of isolating endophytes healthy growing plants of Swertia chirayita (Roxb. ex Fleming) H. Karst. were collected from its natural habitat region across the area of Uttarey West Sikkim, in sterile sampling bags, brought back to the laboratory and stored at $4{ }^{\circ} \mathrm{C}$ until processed. Samples were prepared following the method described by Tucker and Calabrese (2005) and validated with the help of a Botanical Survey of India, Ministry of Environment, Forest and Climate Change, Sikkim Himalayan Regional Centre, and deposited under accession number 0295.

\section{Processing of plant samples for isolation of endophytes}

Processing of $S$. chirayita samples for isolation of endophytes was carried out within $24 \mathrm{~h}$ of their sampling. The samples were segregated into leaves, stem and roots. A soft brush was used to remove soil adhering to the roots followed by rinsing all the plant segments with distilled water. Then the surface sterilization process was carried out by a modified method of Anjum and Chandra (2015) under aseptic conditions by soaking in $70 \%$ ethanol for one minute, in 5\% Sodium Hypochlorite for $10 \mathrm{~min}$ and finally rinsing with sterile distilled water few times. The surface sterilization protocol was validated by plating $1 \mathrm{ml}$ of water from the last rinse of the surface-sterilized samples in a suitable medium and observed for any kind of microbial growth during incubation (Pleban et al. 1995).

The outer layer of the surface-sterilized stems and roots was removed, remaining tissues were cut into smaller segments of $50 \times 50 \mathrm{~mm}$ size and transferred to nutrient medium PDA. The plates, including those containing water from the last rinse, were then incubated at $28 \pm 2{ }^{\circ} \mathrm{C}$. The culture plates were observed regularly for microbial growth arising from the plant sections and any distinctive colonies were sub-cultured in respective nutrient media to obtain axenic 
fungal cultures, which were then transferred to PDA slopes and stored at $4{ }^{\circ} \mathrm{C}$.

\section{Isolation and colonization frequency of endophytes}

Isolation and colonization frequency of endophytes in the sampled segments of $S$. chirayita were calculated by the method described by Huang et al. (2008). Isolation frequency $=$ Number of microbial isolates obtained from the plant segments/total number of segments inoculated.

Colonization frequency $(\%)=($ Total number of plant segments colonized by endophytic fungi/total number of segments inoculated) $\times 100$.

\section{Screening the isolated microorganisms for potential activities}

\section{Phosphate solubilization potential}

Loopful of mycelium along with the spores of all isolated endophytes were transferred to Pikovskaya's Agar medium (PKA) and incubated at $28 \pm 2{ }^{\circ} \mathrm{C}$ for 5 days. The plates were observed for a zone of clearance around the microbial growth during incubation. Plates showing zone of clearance around fungal colony were considered positive for phosphate solubilization by the respective isolates (Pandey et al. 2006), which were measured for isolates' phosphate solubilization potential.

\section{CMCase activity}

Loopful of mycelium along with the spores of all isolated endophytes were inoculated on CMC agar medium [Minimal salt medium supplemented with $0.2 \%$ carboxymethyl cellulose (CMC), $1.5 \%$ Agar] and incubated at $28 \pm 2{ }^{\circ} \mathrm{C}$ for 5 days. The microorganisms capable of producing CMCase enzyme were expected to break down carboxymethyl cellulose to simple sugars, a halo around the microbial colonies, indicated CMCase activity (Chang and Yang 2009).

\section{Amylase activity}

Loopful of mycelium along with the spores of all isolated endophytes were inoculated in a starch agar medium and incubated at $28 \pm 2{ }^{\circ} \mathrm{C}$ for 5 days. Microorganisms with potential amylase activity were expected to hydrolyze starch into simple sugars, which was detected flooding plates with iodine solution. A halo around the colonies indicated a positive test for amylase enzyme activity in endophyte isolate (Aneja 2003).

\section{Siderophores activity}

Siderophores activity capability of endophytes was detected using Universal Chrome Azurol Sulphonate (CAS) assay. CAS solution: (a). $10 \mathrm{ml}$ of iron (III) solution (1 mM of $\mathrm{FeCl}_{3} \cdot 6 \mathrm{H}_{2} \mathrm{O}$ in $\left.10 \mathrm{mM} \mathrm{HCl}\right)$ was mixed with $\mathrm{CAS}(60.5 \mathrm{mg}$ in $50 \mathrm{ml}$ of demineralized water); (b). CTAB solution was prepared dissolving $72.9 \mathrm{mg}$ cetrimonium bromide in $40 \mathrm{ml}$ of water. Both a. and b. solutions were mixed slowly to produce a dark blue solution.

PIPES medium: $30.24 \mathrm{~g}$ of 1.4- piperazine diethane sulfonic acid (PIPES HiMedia) was dissolved in $900 \mathrm{ml}$ of water, $6 \mathrm{~g}$ of $\mathrm{NaOH}$ was added to raise the $\mathrm{pH}$ to the $\mathrm{pKa}$ of PIPES (pH 6.8). $15 \mathrm{~g}$ of agar was added before sterilization of the medium.

CAS solution and PIPES media were mixed and poured onto sterile Petri dishes. Loopful of mycelium along with the spores of isolated endophytes were inoculated in the bluecoloured medium and incubated at $28 \pm 2{ }^{\circ} \mathrm{C}$ for 5 days. The results were interpreted based on the colour change of the medium from blue to orange halo around the inoculated culture due to the iron chelating ability of the microbial isolates (Nagpure et al. 2014).

\section{Chitinase activity}

Chitinolytic activity of the endophytes was assayed using a modified colloidal chitin medium (Rojas-Avelizapa et al. 1999). Loopful of mycelium along with the spores of the endophytes were inoculated on minimal salt agar plates supplemented with 5\% (w/v) chitin. The plates were incubated at $28 \pm 2{ }^{\circ} \mathrm{C}$ for 5 days followed by staining with $0.1 \%$ (w/v) Congo red solution and de-staining with $1 \mathrm{~N} \mathrm{NaCl}$ solution. Formation of a halo around the microbial colonies indicated a positive result for chitinolytic activity (Nagpure et al. 2014).

\section{Protease activity}

The protease activity of the microorganisms was screened using Skim milk agar medium. The plates were inoculated with loopful of mycelium along with the spores of endophytes and incubated at $28 \pm 2{ }^{\circ} \mathrm{C}$ for 5 days. The plates were observed for a zone of clearance around the colonies indicating protease activity in isolates (Aneja 2003).

\section{Indoleacetic acid production}

Indole Acetic Acid (IAA) production by the endophytes was assayed using a modified protocol of Gordon and Weber (1951). Loopful of mycelium along with spores of the fungal endophytes were inoculated in $50 \mathrm{ml}$ Potato Dextrose Broth (PDB) supplemented with 0.1\% L-Tryptophan. After 
an incubation period of 8 days at $28 \pm 2{ }^{\circ} \mathrm{C}$, the culture broth was filtered through sterile Whatman filter paper No. 1 and the filtrate was tested for the presence of IAA using Salkowski reagent. Equal amount of the reagent was mixed with the filtrate and incubated for $30 \mathrm{~min}$ in dark. Due to IAA activity pink colour was developed, which was optically measured at $530 \mathrm{~nm}$. Concentration of IAA in the samples was determined from the standard curve of IAA. The mycelium mass retained on filter paper was dried and weighed. IAA production by individual isolates was compared with the dry weight of the mycelium of respective endophytes.

\section{Hydrogen cyanide production}

Hydrogen cyanide ( $\mathrm{HCN}$ ) has been associated with the induction of systemic resistance in some plants (Wei 1991), and antagonistic nature against phytopathogens (Voisard et al. 1989). HCN production by endophytes was tested using strips of sterile Whatman filter paper soaked in a solution of $0.3 \%$ Picric acid and $1.5 \%$ sodium carbonate. The paper strips were placed inside PDA slopes inoculated with loopful of mycelium along with the spores of pure culture of endophytes followed by incubation at $28 \pm 2{ }^{\circ} \mathrm{C}$ after sealing the tubes tightly with parafilm. Results were interpreted based on the colour change of strips from yellow to brown/ reddish brown (Potshangbam et al. 2017).

\section{Interactions between endophyte and test pathogens}

Antagonistic potential of the test endophytes was assayed by Dual culture method. Endophytes were subjected to dual culture assay against phytopathogens: Fusarium solani ITCC 7453, Colletotrichum gloeosporioides ITCC 5514, Alternaria alternata ITCC 7415, Pestalotiopsis theae ITCC 6599 and Sclerotinia sclerotiorum ITCC 7853 by referring to the types of interactions between an endophyte and a test pathogen described by Chowdhary and Kaushik (2015). The test pathogens and the fungal endophytes were placed at the opposite end on PDA plates and the interaction between cultures was recorded during the incubation period of $7-14$ days at $28 \pm 2{ }^{\circ} \mathrm{C}$.

\section{Phylogenetic analysis of the most productive isolate}

One of the isolates UTCRF6 found to be the most active and many functionalities was selected for its identification. Its phylogenetic analysis was carried out at National Centre for Microbial Resource (NCMR), National Centre for Cell Science, Pune India. For molecular analysis, genomic DNA was isolated by the standard phenol/chloroform extraction method (Sambrook et al. 1989), followed by PCR amplification of the ITS regions using universal primers ITS1 [5'-TCC
GTA GGT GAA CCT GCG G -3'] and ITS4 [5'-TCC TCC GCT TAT TGA TAT GC $\left.-3^{\prime}\right]$.

The amplified ITS PCR product was purified by PEG$\mathrm{NaCl}$ precipitation and directly sequenced on an $\mathrm{ABI}^{\circledR}$ 3730XL automated DNA sequencer (Applied Biosystems, Inc., Foster City, CA) as per the manufacturer's instructions. Essentially, sequencing was carried out from both ends so that each position was read at least twice. Lasergene package was used to carry out the assembly followed by NCBI BLAST against sequences from type material for tentative identification (Boratyn et al. 2013). The evolutionary history of the endophyte was inferred using the Neighbor-Joining method (Saitou and Nei 1987). The percentage of replicate trees in which the associated taxa clustered together in the bootstrap test (1000 replicates) were analyzed (Felsenstein 1985). The evolutionary distances were computed using the Jukes-Cantor method (Kimura 1980). The analysis involved 14 nucleotide sequences. All positions with less than $95 \%$ site coverage were eliminated and the final dataset was left with a total of 359 positions. MEGA6 was used for evolutionary analyses (Tamura et al. 2013).

\section{Statistical analysis}

All tests were performed in triplicates and descriptive statistics (Mean and standard deviation) were used to interpret the data obtained from enzyme assays and Indole Acetic Acid production. MS Excel was used extensively for all the statistical analysis.

\section{Results and discussion}

Swertia chirayita is one of the most used medicinal plant for the preparation of homemade herbal concoctions for various illnesses in the state of Sikkim (Badola and Pradhan 2013). Unaccounted and uncontrolled exploitation of this herb, along with a very narrow range of natural geographical habitat in the Himalayan belt has put a lot of pressure on this precious bioresource. With the loss of this plant species, microbial flora associated with this plant will face the impact of exploitation, which remains unexplored till now. Therefore, our project was planned in collaboration with three research institutes (in India and Northern Ireland) and undertaken to secure such valuable microflora and test for their hidden potential.

We have listed the isolation frequency of endophytic fungi from different segments of $S$. chirayita in Table 1 . Maximum number of endophytes were isolated from the root tissue $(40 \%)$ followed by stems $(15.91 \%)$ and leaves (7.14\%), respectively. Altogether, $21.69 \%$ of plant segments were found to be colonized by fungal endophytes. Positive correlation between colonization frequency and isolation frequency was observed. 
Table 1 Isolation frequency and colonization frequency of endophytic fungi from different segments of Swertia chirayita

\begin{tabular}{llccc}
\hline & Leaves & Stem & Roots & Total \\
\hline Number of segments inoculated & 35 & 34 & 34 & 103 \\
Number of isolates obtained & 3 & 8 & 12 & 23 \\
Isolation frequency (numbers) & 0.08 & 0.23 & 0.35 & 0.22 \\
Colonization frequency (percent) & 8.57 & 23.52 & 35.29 & 22.33 \\
\hline
\end{tabular}

Total of 36 fungal isolates were obtained from the different segments of $S$. chirayita, of which twelve strains were selected for further study on the basis of distinct morphological characteristics cultured on PDA medium. These were screened for secretion of enzymes of industrial significance CMCase and amylase, protease, chitinase; antimicrobial properties including siderophores and hydrogen cyanide; for the production of plant growth-promoting factors viz. IAA and phosphatase. Six of them showed activity for IAA production, eight for protease, three for chitinase enzyme, two for siderophores activity, four for amylase and two isolates were CMCase producers. The results are presented in Figs. 1 and 2, respectively none of the isolates could solubilize inorganic phosphate and produce hydrogen cyanide under in vitro conditions.

Among all endophyte isolates, UTCRF6 was found to be most productive with respect to Indoleacetic Acid synthesis $(63.0 \pm 2.53 \mu \mathrm{g} / \mathrm{ml})$ and antimicrobial potential such as protease $(3.33 \pm 0.58 \mathrm{~mm})$, siderophores $(4.67 \pm 0.58 \mathrm{~mm})$, and chitinase $(6.33 \pm 0.58 \mathrm{~mm})$, responsible for inducing host resistance. It is evident from Fig. 1 that few endophytes were better than UTCRF6 in the production of some of the metabolites, however, the isolate UTCRF6 was able to synthesize most of the tested metabolites, with possible significance to their use in agriculture and bioresource management.

IAA produced by different bacterial and fungal endophytes associated with plant growth-promoting ability has been reported earlier (Zhang et al. 2018). Chitinolytic
Fig. 1 Enzyme and Siderophore activities of endophytes
Fig. 2 Indoleacetic Acid production by the test endophytes. The amount of IAA produced ( $\mu \mathrm{g} / \mathrm{ml}$ of growth medium) was compared with the dry biomass of the fungal mat (mg dry weight $/ \mathrm{ml}$ of nutrient medium). Blue bars represent the dry weight of the fungal mycelia, and red dots represent the amount of IAA produced by the respective endophytes

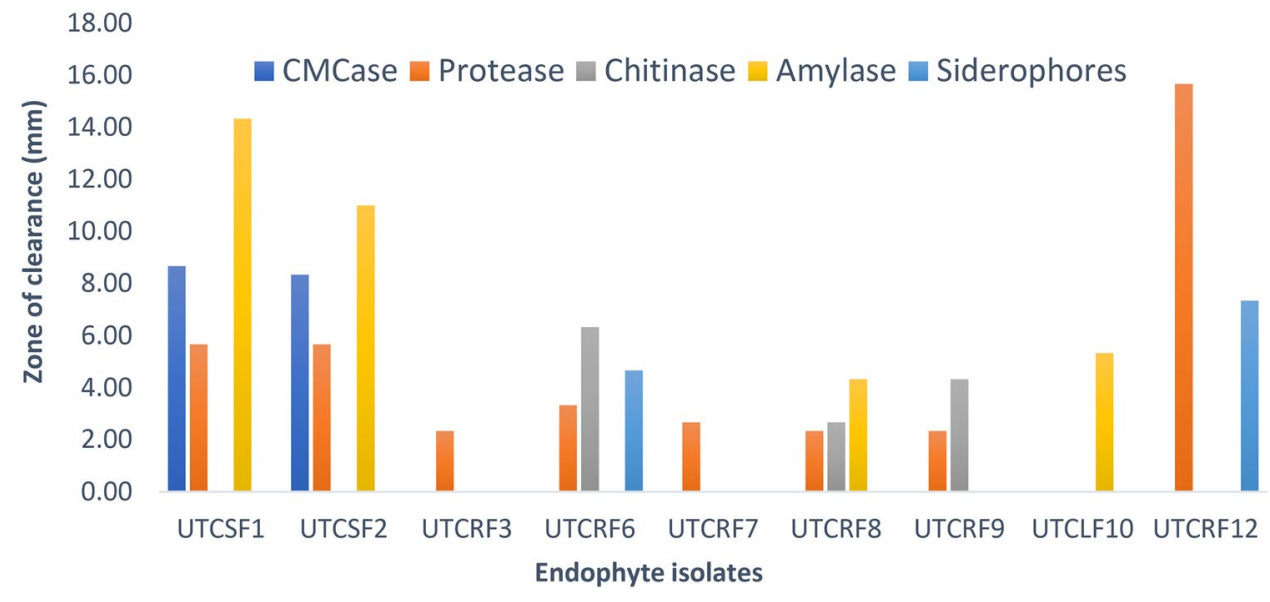

Dry weight of mycelia IAA production

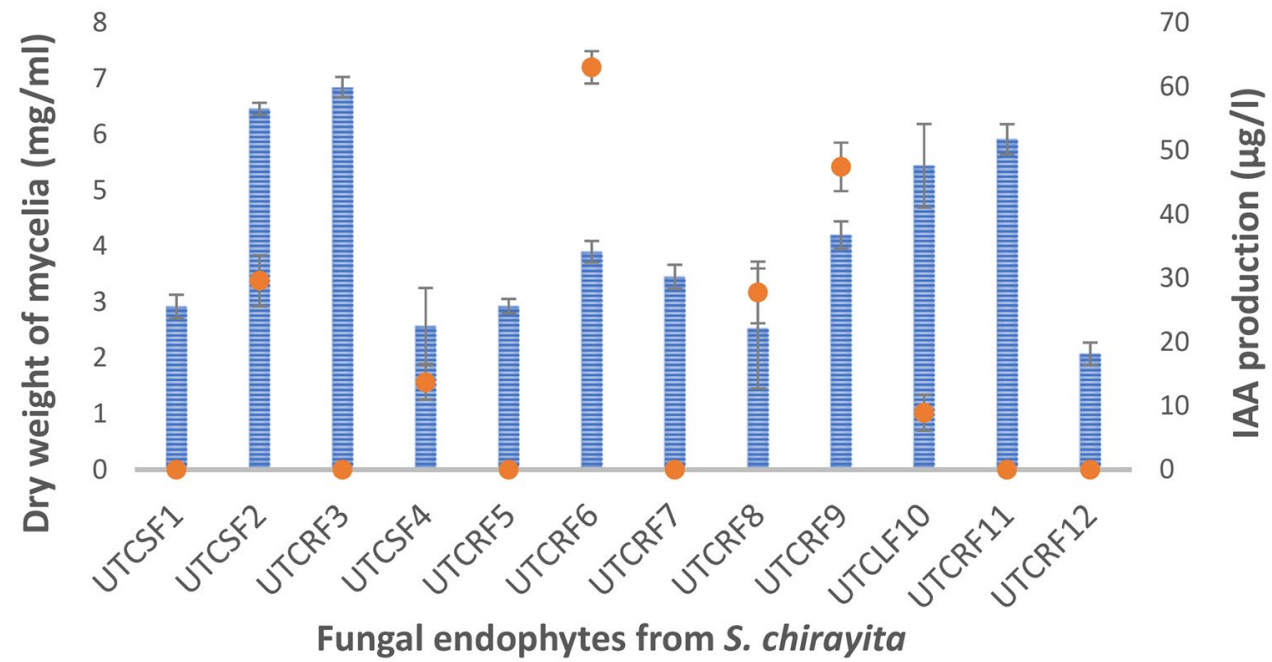


enzymes, produced by endophytes, have been known to trigger host responses against the invading pathogens which may result in increased resistance of the host plant (Zheng et al. 2017). Siderophores activity by endophytes has been associated with their virulence factor, and their synthesis under in vitro conditions has been described by Kajula et al. (2010). Biocontrol potential of protease enzyme is known in fungal strains (Elad and Kapat 1999).

The isolate UTCRF6 was also able to restrict the growth of tested phytopathogens Fusarium solani ITCC 7453, Colletotrichum gloeosporioides ITCC 5514, Alternaria alternata ITCC 7415, Pestalotiopsis theae ITCC 6599 and Sclerotinia sclerotiorum ITCC 7853 under dual culture assay exhibiting Class 3 interaction, where both pathogen and endophyte grew towards each other and zone of inhibition was formed and maintained for another week (Table 2 and Fig. 3).
The test pathogenic organisms used in our dual culture study were selected considering the implications of the pathogens on the food or cash crops of Sikkim. Majority of the farmers residing in Sikkim are highly dependent on cash crops such as large cardamom, buckwheat, mandarin orange, etc. to run their livelihood.

Phytopathogens are known to cause havoc in the agriculture system resulting in heavy financial loses to the farmers. Colletotrichum gloeosporioides has been reported to cause severe blight of Amomum subulatum (large cardamom) in Sikkim resulting in the total destruction of a high yielding variety of cardamom plant, Varlangey (Saju et al. 2013). Similarly, Alternaria alternata was responsible for causing leaf spots in Tamarillo (Cyphomandra betacea) in Sikkim (Gupta and Choudhary 1994). A. alternata was a causative agent for leaf spots disease in Tea as reported from China (Zhou and Xu 2014). Pestalotiopsis theae infection of tea
Table 2 Interactions of Swertia chitrayita endophytes with phytopathogenic fungi

\begin{tabular}{llllll}
\hline $\begin{array}{l}\text { Endophyte iso- } \\
\text { lates (1-12) }\end{array}$ & \multicolumn{4}{l}{ Type of interaction observed against test phyto-pathogens } & \\
\cline { 2 - 6 } & $\begin{array}{l}\text { Pestalotiopsis } \\
\text { theae }\end{array}$ & $\begin{array}{l}\text { Colletotrichum } \\
\text { gloeosporioides }\end{array}$ & $\begin{array}{l}\text { Alternaria } \\
\text { alternata }\end{array}$ & Fusarium solani & $\begin{array}{l}\text { Sclerotinia } \\
\text { sclerotio- } \\
\text { rum }\end{array}$ \\
\hline UTCSF1 & Class 3 & Class 5 & Class 5 & Class 3 & Class 3 \\
UTCSF2 & Class 3 & Class 3 & Class 5 & Class 3 & Class 3 \\
UTCRF3 & Class 1 & Class 5 & Class 5 & Class 1 & Class 1 \\
UTCSF4 & Class 5 & Class 3 & Class 5 & Class 5 & Class 5 \\
UTCRF5 & Class 3 & Class 3 & Class 5 & Class 3 & Class 3 \\
UTCRF6 & Class 3 & Class 3 & Class 3 & Class 3 & Class 3 \\
UTCRF7 & Class 7 & Class 6 & Class 6 & Class 6 & Class 5 \\
UTCRF8 & Class 3 & Class 5 & Class 5 & Class 3 & Class 3 \\
UTCRF9 & Class 3 & Class 3 & Class 3 & Class 3 & Class 3 \\
UTCLF10 & Class 3 & Class 6 & Class 6 & Class 6 & Class 3 \\
UTCRF11 & Class 5 & Class 6 & Class 6 & Class 3 & Class 5 \\
UTCRF12 & Class 3 & Class 7 & Class 7 & Class 7 & Class 7 \\
\hline
\end{tabular}
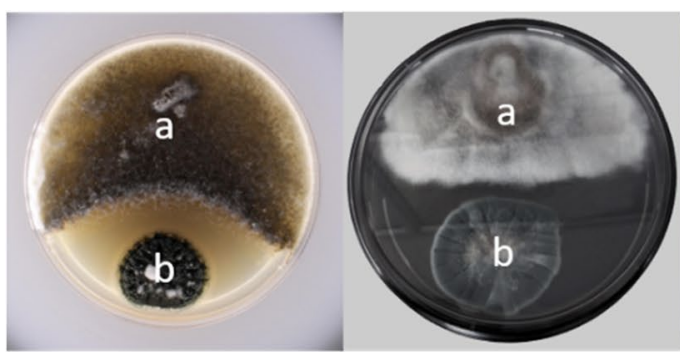

(a) Pestalotiopsis theae sclerotiorum

(b) UTCRF6 (b) UTCRF6

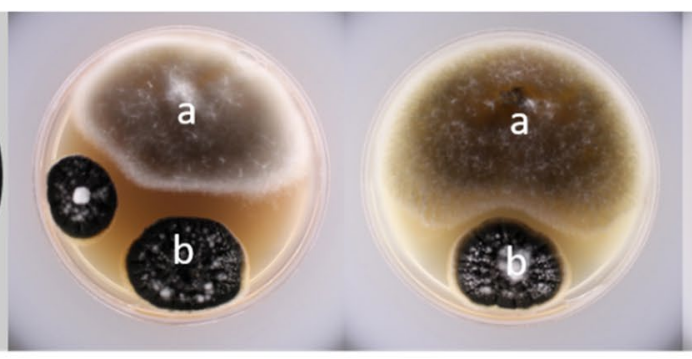

(a) Fusarium solani

(b) UTCRF6

\begin{abstract}
(a) Colletotrichum gloeosporioides
\end{abstract}

(b) UTCRF6

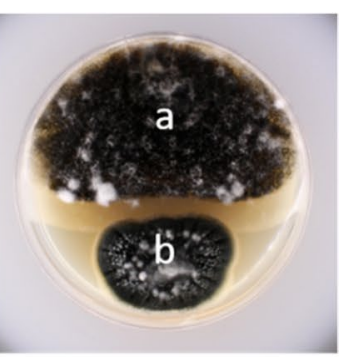

(a) Alternaria alternata

(b) UTCRF6
Fig. 3 Interaction of endophytes with phytopathogens by dual culture method. Culture conditions: Loopful of inoculum of test pathogen and endophyte isolate was inoculated at the opposite end of a plate containing PDA medium and the results were analyzed after 14 days of incubation at $28{ }^{\circ} \mathrm{C}$ 
leaves is a major concern in Sub Himalayan region of West Bengal (Harikamal et al. 2015). Tea is one of the most popular beverages of the world and infection of the leaves by fungal pathogens such as A. alternate and $P$. theae will have a severe impact on the yield. Sclerotinia sclerotiorum has been known to infect and cause stem rot in buckwheat plants (Morrall et al. 1976). Fusarium solani was isolated from Citrus reticulata, one of the major cash crops of Sikkim (Chattopodhyay and Sengupta 1967).

Microscopic characteristics of the endophyte isolate UTCRF6 are as follows; hyphae: entire, smooth, hyaline with width $6.59 \mu \mathrm{m}$, conidiophore: length $13.36 \mu \mathrm{m}$ and width $2.30 \mu \mathrm{m}$, conidia: radius $1.01 \mu \mathrm{m}$, phialide: length $10.01 \mu \mathrm{m}$ and width $2.32 \mu \mathrm{m}$, which showed similarity with Penicillium sp. Molecular characterization of the endophyte was carried out by sequencing a section of rDNA (using universal primers ITS 1 and ITS 4) and Basic Local Alignment tool (BLAST) of the National Centre for Biotechnology Information was used to match its homology with congeneric species from the database. The sequence of the endophyte had a similarity of $99 \%$ to Penicillium citrinum which has been submitted to NCBI GenBank under the accession number MK474614. Phylogenetic tree showing the relationship of UTCRF6 with other species of Penicillium is shown in Fig. 4. The fungal endophyte (UTCRF6) has been deposited at National Centre for Microbial Resource (NCMR), National Centre for Cell Science, Pune under accession number MCC 1810.

Our report is on the isolation and characterization of Penicillium citrinum from a medicinal plant $S$. chirayita, near to its overexploitation. In other published reports of Penicillium citrinum has been isolated as endophyte from

(A) Morphological feature of UTCRF6 as seen on PDA plate,

(B) Microscopic structures of UTCRF6

(C) Phylogenetic chart showing relationship of UTCRF6 against other species under Penicillium genus

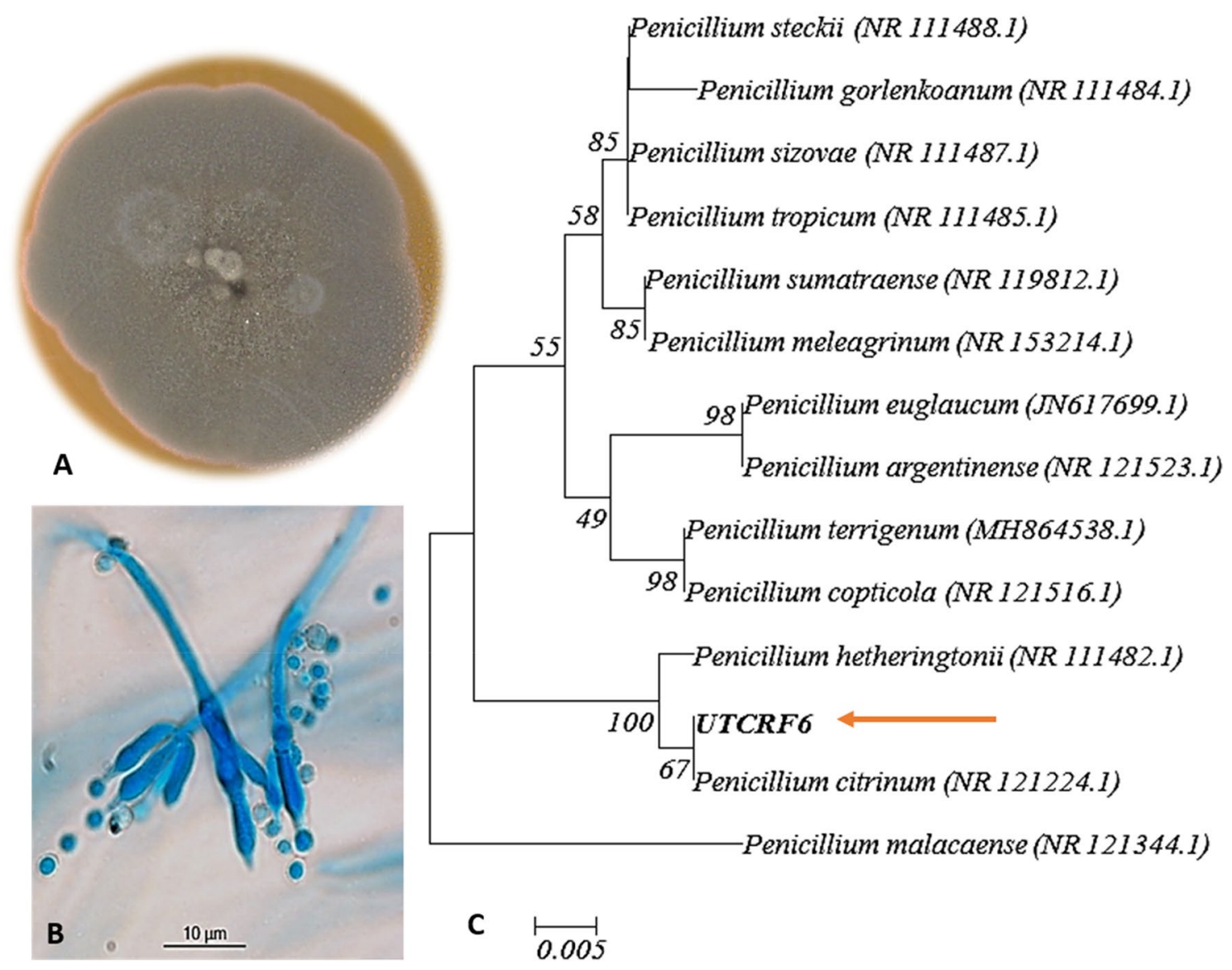

Fig. 4 Characterization of endophyte isolate UTCRF6. A Morphological feature of UTCRF6 as seen on PDA plate, B Microscopic structures of UTCRF6, C Phylogenetic chart showing relationship of UTCRF6 against other species under Penicillium genus 
other plants such as Bruguiera sexangular and Scoparia dulcis, among which one of the strains obtained from $B$. sexangular was found to produce antibacterial metabolite showing antagonistic property against Bacillus subtilis, Micrococcus tetragenus and Bacillus cereus (Zheng et al. 2016). Khan et al. (2008) have isolated a strain of $P$. citrinum, from the roots of Ixeris repens, that was able to produce plant growth-promoting hormone, gibberellin, under in vitro conditions. Urooj et al. (2018) have reported several species of Penicillium, including $P$. citrinum, as endophytes of various plant species, which were able to suppress root rotting fungi in sunflower when applied alone or along with soil amended with neem cake. $P$. citrinum isolated from Ceratonia siliqua was able to produce five novel compounds (El-Neketi et al. 2013). One of the strains of Penicillium endophyte, Penicillium citrinum LWL4, was able to promote plant growth irrespective of the presence or absence of root rot disease caused by Sclerotium rolfsii in sunflower compared to plants under the control group (Waqas et al. 2015). Banana plantlets treated with the strain of endophyte, P. citrinum BTF08, showed delayed progression of symptoms, lower rate of disease occurrence and disease severity when infected with Fusarium oxysporum f. sp. cubense race 4 (FocR4) (Ting et al. 2012).

\section{Conclusion}

S. chirayita were found to harbour many fungal endophytes, their isolation and characterization is reported in this paper first time. Qualitative screening of all endophytes under in vitro conditions exhibited useful characteristics with their possible applications in agriculture. Among all endophyte-isolates, UTCRF6 identified as Penicillium citrinum was found to be most prolific with the production of chitinase and protease enzymes, and was able to restrict the growth of several phytopathogens. Biosynthesis of enzymes, antimicrobial property, production of host secondary metabolites, studied in this project, ascertains the potential of endophyte isolates for further study on a larger scale for application of their bioactivities.

\footnotetext{
Acknowledgements The authors would like to thank the Forest, Environment and Wildlife Management Department, Government of Sikkim for permitting us to collect the plant samples for this study; Botanical Survey of India, Ministry of Environment, Forest and Climate Change, Sikkim Himalayan Regional Centre for helping us to validate the plant sample; Division of Plant Pathology, Indian Agricultural Research Institute, New Delhi for providing test phytopathogens for this work; National Centre for Microbial Resource (NCMR), National Centre for Cell Science, Pune for helping us with phenotypic and molecular identification along with storage of our endophyte isolate and Department of Botany, Sikkim University for providing us the required facilities to conduct the research work.
}

Author contributions All co-authors (HS, AKR RC PSN) contributed in conceptualization, methodology, data collection, writing-original manuscript preparation.

Funding This research did not receive any financial grant from funding agencies in the public, commercial, or not-for-profit sectors.

\section{Declarations}

Conflict of interest None.

Open Access This article is licensed under a Creative Commons Attribution 4.0 International License, which permits use, sharing, adaptation, distribution and reproduction in any medium or format, as long as you give appropriate credit to the original author(s) and the source, provide a link to the Creative Commons licence, and indicate if changes were made. The images or other third party material in this article are included in the article's Creative Commons licence, unless indicated otherwise in a credit line to the material. If material is not included in the article's Creative Commons licence and your intended use is not permitted by statutory regulation or exceeds the permitted use, you will need to obtain permission directly from the copyright holder. To view a copy of this licence, visit http://creativecommons.org/licenses/by/4.0/.

\section{References}

Agrawal S, Deshmukh SK, Reddy MS et al (2020) Endolichenic fungi: a hidden source of bioactive metabolites. S Afr J Bot 134:163-186

Aneja KR (2003) Experiments in microbiology, plant pathology and biotechnology, 2nd edn. New Age International, New Delhi

Anjum N, Chandra R (2015) Endophytic bacteria: optimization of isolation procedure from various medicinal plants and their preliminary characterization. Asian J Pharm Clin Res 8:233-238

Badola HK, Pradhan BK (2013) Plants used in healthcare practices by Limboo tribe in South-West of Khangchendzonga Biosphere Reserve, Sikkim, India. Indian J Tradit Knowl 12(3):355-369

Boratyn GM, Camacho C, Cooper PS et al (2013) BLAST: a more efficient report with usability improvements. Nucleic Acids Res 41:W29-W33. https://doi.org/10.1093/nar/gkt282

Chang CH, Yang SS (2009) Thermo-tolerant phosphate-solubilizing microbes for multi-functional biofertilizer preparation. Bioresour Technol 100:1648-1658. https://doi.org/10.1016/j.biortech.2008. 09.009

Chattopodhyay SB, Sengupta SK (1967) Twig blight disease of orange. Sci Cult 33-129

Chowdhary K, Kaushik N (2015) Fungal endophyte diversity and bioactivity in the Indian medicinal plant Ocimum sanctum Linn. PLoS ONE 10:1-25. https://doi.org/10.1371/journal.pone.01414 44

Deshmukh SK, Agrawal S, Prakash V et al (2020) Anti-infectives from mangrove endophytic fungi. S Afr J Bot 134:237-263. https://doi. org/10.1016/j.sajb.2020.01.006

Elad Y, Kapat A (1999) The role of trichoderma harzianum protease in the biocontrol of Botrytis cinerea. Eur J Plant Pathol 105:177-189

El-Neketi M, Ebrahim W, Lin W et al (2013) Alkaloids and polyketides from Penicillium citrinum, an endophyte isolated from the Moroccan plant Ceratonia siliqua. J Nat Prod 76:1099-1104. https://doi. org/10.1021/np4001366

Envis Centre Sikkim Forest Environment and Wildlife Management Department Government of Sikkim (2011) Medicinal and Aromatic plants in Sikkim. http://sikenvis.nic.in/Database/Biodiversi ty_776.aspx. Accessed 26 Apr 2020 
Felsenstein J (1985) Confidence limits on phylogenies: an approach using the bootstrap. Evolution 39:783-791. https://doi.org/10. 1111/j.1558-5646.1985.tb00420.x

Gordon SA, Weber RP (1951) Colorimetric estimation of indoleacetic acid. Plant Physiol 26:192-195

Gupta DK, Choudhary KCB (1994) New leaf spot of tomato caused by Alternaria alternata. Indian J Mycol Plant Pathol 24:238

Harikamal B, Aniruddha R, Shaon KD (2015) Evaluation of plant products and antagonistic microbes against grey blight (pestalotiopsis theae), a devastating pathogen of tea. Afr J Microbiol Res 9:1263-1267. https://doi.org/10.5897/AJMR2015.7391

Huang WY, Cai YZ, Hyde KD et al (2008) Biodiversity of endophytic fungi associated with 29 traditional Chinese medicinal plants. Fungal Divers 33:61-75

Kajula M, Tejesvi MV, Kolehmainen S et al (2010) The siderophore ferricrocin produced by specific foliar endophytic fungi in vitro. Fungal Biol 114:248-254. https://doi.org/10.1016/j.funbio.2010.01.004

Khan S, Hamayun M, Yoon H et al (2008) Plant growth promotion and Penicillium citrinum. BMC Microbiol 8:231. https://doi.org/10. 1186/1471-2180-8-231

Kimura M (1980) A simple method for estimating evolutionary rates of base substitutions through comparative studies of nucleotide sequences. $\mathrm{J}$ Mol Evol 16:111-120. https://doi.org/10.1007/BF01731581

Kshirsagar PR, Chavan JJ, Gaikwad NB et al (2020) Metabolite profiling, antioxidant potential and RP-UFLC determination of bioactive molecules from eight Swertia species. Biocatal Agric Biotechnol 23:101479. https://doi.org/10.1016/j.bcab.2019.101479

Kumar V, Staden VJ (2016) A review of Swertia chirayita (Gentianaceae) as a traditional medicinal plant. Front Pharmacol 6:308. https://doi.org/10.3389/fphar.2015.00308

Morrall RAA, Dueck J, McKenzie DI, McGee DC (1976) Some aspects of Sclerotinia sclerotiorum in Saskatechewan 1970-75. Can Plant Dis Sury 56:56

Nagpure A, Choudhary B, Kumar S, Gupta RK (2014) Isolation and characterization of chitinolytic Streptomyces sp. MT7 and its antagonism towards wood-rotting fungi. Ann Microbiol 64:531541. https://doi.org/10.1007/s13213-013-0686-x

Pandey A, Trivedi P, Kumar B et al (2006) Characterization of a phosphate solubilizing and antagonistic strain of Pseudomonas putida (B0) isolated from a sub-alpine location in the Indian Central Himalaya. Curr Microbiol 53:102-107. https://doi.org/10.1007/ s00284-006-4590-5

Pleban S, Ingel F, Chet I (1995) Control of Rhizoctonia solani and Sclerotium rolfsii in the greenhouse using endophytic Bacillus spp. Eur J Plant Pathol 101:665-672. https://doi.org/10.1007/ BF01874870

Potshangbam M, Devi SI, Sahoo D et al (2017) Functional characterization of endophytic fungal community associated with Oryza sativa $\mathrm{L}$. and Zea mays L. Front Microbiol 8:1-15. https://doi.org/ 10.3389/fmicb.2017.00325

Pradhan BK, Badola HK (2012) Effect of storage conditions and storage periods on seed germination in eleven populations of Swertia chirayita : a critically endangered medicinal herb in Himalaya. Sci World J 2012:1-9. https://doi.org/10.1100/2012/128105

Rai L, Prasad P, Sharma E (2000) Conservation threats to some important medicinal plants of the Sikkim Himalaya. Biol Conserv 93:27-33. https://doi.org/10.1016/S0006-3207(99)00116-0

Rajulu MBG, Thirunavukkarasu N, Suryanarayanan TS et al (2011) Chitinolytic enzymes from endophytic fungi. Fungal Divers 47:43-53. https://doi.org/10.1007/s13225-010-0071-z

Redecker D, Kodner R, Graham LE (2000) Glomalean fungi from the Ordovician. Science 289:1920-1921

Rojas-Avelizapa LI, Cruz-Camarillo R, Guerrero MI et al (1999) Selection and characterization of a proteo-chitinolytic strain of Bacillus thuringiensis, able to grow in shrimp waste media. World J
Microbiol Biotechnol 15:299-308. https://doi.org/10.1023/A: 1008947029713

Saitou N, Nei M (1987) The neighbor-joining method: a new method for reconstructing phylogenetic trees. Mol Biol Evol 4:406-425. https://doi.org/10.1093/oxfordjournals.molbev.a040454

Saju KA, Deka TN, Gupta U et al (2013) Identity of Colletotrichum infections in large cardamom (Amomum subulatum Roxb.). J Spices Aromat Crop 22:101-103

Sambrook J, Fritsch EF, Maniatis T (1989) Molecular cloning: a laboratory manual. Cold spring harbor laboratory press, New York

Schwyn B, Neilands JB (1987) Universal chemical assay for the detection and determination of siderophores. Anal Biochem 160:47-56. https://doi.org/10.1016/0003-2697(87)90612-9

Shentu X, Zhan X, Ma Z et al (2014) Antifungal activity of metabolites of the endophytic fungus Trichoderma brevicompactum from garlic. Braz J Microbiol 45:248-254. https://doi.org/10.1590/S151783822014005000036

Tamura K, Stecher G, Peterson D et al (2013) MEGA6: molecular evolutionary genetics analysis version 6.0. Mol Biol Evol 30:2725-2729

Thomas S, Patil AB, Salgaonkar PN et al (2020) Screening of bacterial isolates from seafood-wastes for chitin degrading enzyme activity. Chem Eng Process Tech 5(1):1-8

Ting ASY, Mah SW, Tee CS (2012) Evaluating the feasibility of induced host resistance by endophytic isolate Penicillium citrinum BTF08 as a control mechanism for Fusarium wilt in banana plantlets. Biol Control 61:155-159. https://doi.org/10.1016/j. biocontrol.2012.01.010

Tucker AO, Calabrese L (2005) The use and methods of making a herbarium/plant specimens an Herb Society of America guide. The Herb Society of America, Kirtland

Urooj F, Farhat H, Ali SA et al (2018) Role of endophytic Penicillium species in suppressing the root rotting fungi of sunflower. Pak $\mathbf{J}$ Bot 50:1621-1628

Vega FE (2018) The use of fungal entomopathogens as endophytes in biological control: a review. Mycologia 110:4-30. https://doi.org/ 10.1080/00275514.2017.1418578

Voisard C, Keel C, Haas D, Dèfago G (1989) Cyanide production by Pseudomonas fluorescens helps suppress black root rot of tobacco under gnotobiotic conditions. EMBO J 8:351-358

Waqas M, Khan AL, Hamayun M et al (2015) Endophytic fungi promote plant growth and mitigate the adverse effects of stem rot: an example of Penicillium citrinum and Aspergillus terreus. J Plant Interact 10:280-287. https://doi.org/10.1080/17429145.2015.1079743

Wei G (1991) Induction of systemic resistance of cucumber to Colletotrichum orbiculare by select strains of plant growth-promoting rhizobacteria. Phytopathology 81:1508. https://doi.org/10.1094/ Phyto-81-1508

Zhang Y, Kang X, Liu H et al (2018) Endophytes isolated from ginger rhizome exhibit growth promoting potential for Zea mays. Arch Agron Soil Sci 64:1302-1314. https://doi.org/10.1080/03650340. 2018.1430892

Zheng C-J, Huang G-L, Xu Y et al (2016) A new benzopyrans derivatives from a mangrove-derived fungus Penicillium citrinum from the South China Sea. Nat Prod Res 30:821-825. https://doi.org/ 10.1080/14786419.2015.1072712

Zheng YK, Miao CP, Chen HH et al (2017) Endophytic fungi harbored in Panax notoginseng: diversity and potential as biological control agents against host plant pathogens of root-rot disease. J Ginseng Res 41:353-360. https://doi.org/10.1016/j.jgr.2016.07.005

Zhou LX, Xu WX (2014) First report of Alternaria alternata causing leaf spots of tea ( Camellia sinensis ) in China. Plant Dis 98:697697. https://doi.org/10.1094/PDIS-10-13-1086-PDN

Publisher's Note Springer Nature remains neutral with regard to jurisdictional claims in published maps and institutional affiliations. 